\title{
PERINATAL ASPECTS AND AUTISM SPECTRUM DISORDER: AN UPDATE REVIEW
}

\author{
Luiza Emylce Pelá Rosado1,2, Matheus Maia Garcia², Ana Cláudia do Nascimento Coutinho² \\ ${ }^{1}$ Hospital Materno Infantil of Goiânia, Goiás, Brazil \\ 2 Pontificial University of Goiás, Goiânia, Goiás, Brazil.
}

\begin{abstract}
Autistic Spectrum Disorder (ASD) is understood as a group of phenotypic conditions that have in common changes in the development of sociability and communication. Methods: This is a narrative review aiming to update the proposed theme. We used population - based studies such as cohorts, case - control studies as well as previous reviews, published at PubMed, SciELO-LILACS and Cochrane library between January 2018 and May 2019. We used the descriptors: autistic disorder, combined with pregnancy and the MeSH Terms: Autism Spectrum Disorder, combined with pregnancy. 52 studies were selected and, after exclusion criteria, 34 composed this review. Results/Conclusion: Throughout the analysis of results, we could observe, despite of genetic causes, that during the whole pregnancy and postpartum period, the interaction of the pregnant women with the environment and some risk factors that may interfere in maternal-fetal health, such as parent's age, race, being migrants, hypertension, diabetes, use of anticonvulsants, acetaminophen, fetal growth restriction, pre-eclampsia, excessive weight gain and labor complications that showed association to ASD, while alcohol, smoking, folic acid use and vaccination had no association. It's up to health professionals to educate themselves even more so as to anticipate, as far as possible, the disorder and know how to deal with special children, free from prejudices and stigmata.
\end{abstract}

Key Words: autistic spectrum disorder, autism, pregnancy, growth and development.

\section{INTRODUCTION}

Recognized as a clinical entity by Leo Kanner in 1943, Autism Spectrum Disorder (ASD) is understood as a group of phenotypic conditions that have in common changes in the development of sociability and communication characterized by deficits in verbal and non-verbal communication, imparement in socialization, restricted and sometimes stereotyped patterns of behavior, interests, and activities. ${ }^{1}$ Much is discussed and studied about the etiological theory of ASD. A recent study suggests

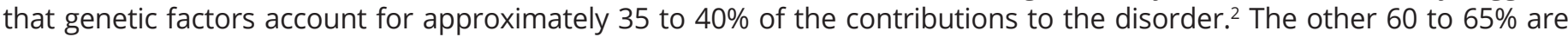
probably due to factors such as environmental, prenatal, perinatal and postnatal. ${ }^{3}$ Because it is a developmental disorder, complications in the peri or neonatal period may be particularly important factors to be considered. ${ }^{3}$

Since 1996 the epidemiology of ASD has been scientifically researched. ${ }^{3}$ It has become clear that, in recent years, such disorder is more prevalent than previously thought. ${ }^{3}$ A report from the Center for Disease Control and Prevention (CDC) of April 2018 indicates that the prevalence of ASD is: 1:59 among 8-year-old children in the US, ${ }^{4}$ thus becoming the most frequent developmental disorder, with high personal, family and social impact. ${ }^{5}$ It has also been observed a higher incidence of autism among boys than girls, with reported proportions of about 3.5-4.0 to 1.6

\section{METHODS}

To compose this review, we searched the databases PubMed, SciELO-LILACS and Cochrane library between January 2018 and May 2019. We used the descriptors- autistic disorder, combined with pregnancy, through the Boolean operator "AND" and the MeSH Terms - Autism Spectrum Disorder, combined with pregnancy, through the Boolean operator "AND".

Financial support: The costs for this research were done by the researchers themselves.

Conflicts of interest: There were no conflicts of interest.

Submitted: $21 / 06 / 2019$

Accepted: 16/07/2020

Study carried out at Pontifical Catholic University of Goiás, Goiânia, Goiás, Brazil.

Copyright Rosado et al. This is an Open Access article distributed under the terms of the Creative Commons Attribution License, which permits unrestricted use, distribution, and reproduction in any medium, provided the original work is properly cited. 
We choose population-based studies such as cohorts, case-control studies, and meta-analyzes. The selected studies were in Portuguese, English or Spanish.

The inclusion criteria were: systematic reviews and population-based studies in which the mothers' exposure and their offspring were well defined and the outcome described.

We excluded those studies which included other pre-defined diagnoses, with low sampling or unsatisfactory follow-up of the children, inadequate research design or without statistical calculation, as well as studies that dealt mainly with the genetic causes of the disorder. 52 studies were selected and, after exclusion criteria, 34 composed this review.

\section{RESULTS/DISCUSSION}

\section{Prenatal risk factors}

\section{a. Unchangeable prenatal risk factors}

The association of non-pathological prenatal risk factors to ASD was observed by Wang et al., ${ }^{7}$ concluding that features like advanced maternal and paternal age (> 35 years); parent's race (white or Asian) and parental wide-ranging university education, were significantly associated with the development of ASD. In this study, black and hispanic paternity showed a negative association. ${ }^{7}$ However, when studying the effects of immigration on neurodevelopment, Abdullahi et al. ${ }^{8}$ revealed that children of immigrant women, from underdeveloped countries, were more likely to develop ASD with intellectual deficit. Multiparity was shown as a protection factor, ${ }^{8}$ which contrasts with Brimacombe et al., ${ }^{9}$ that found higher risk with the same variable. It should be emphasized that male children, as in other studies, represent a positive association factor. $6,7,10$

\section{b. Prenatal risk factors: medication, alcohol and tobacco}

\section{Folic acid}

Wang et al. ${ }^{7}$ reported that maternal use of folic acid supplements would reduce the risk of ASD compared to those without supplementation relative risk (RR): 0.77, 95\% confidence interval (CI) 0.64-0.93.

Surén et al. ${ }^{11}$ observed that women who started folate from 4 weeks before conception were more likely to have a higher socioeconomic level and schooling, planned gestation, were neither smokers nor obese. Folate supplementation for the last 4 weeks before conception up to 8 weeks after the discovery of pregnancy was found to be associated with a lower risk of ASD in children, odds ratio (OR): 0.61 (95\% Cl, 0.41-0.90). ${ }^{11}$ Steenweg-de Graaff et al. ${ }^{12}$ found no association between maternal folate concentration in early stages of gestation with autistic traits in their offspring at age $6 .{ }^{12}$

\section{Use of antidepressant during pregnancy}

Rai et al..$^{13}$ defined that exposure to antidepressants, in general, during pregnancy was associated with a higher probability of diagnosing autism in the offspring other than the exposure to a maternal psychiatric disorder without the use of antidepressants OR: 1.45 (95\% Cl, 1.13-1.85). ${ }^{13}$

Croen et al. ${ }^{14}$ demonstrated an increase in the risk of ASD associated with treatment with Selective Serotonin Reuptake Inhibitors (SSRIs) by the mother during the year before delivery with adjusted odds ratio (AOR): 2.2 (95\% Cl 1.2-4.3), but with strongest effect associated with the treatment during the first trimester of gestation AOR: $3.8(95 \% \mathrm{Cl}, 1.8-7.8) .{ }^{14}$

On the other hand, Sørensen et al. ${ }^{15}$ concluded that there was no significant association between prenatal exposure to antidepressant medication and autism spectrum disorders in offspring ${ }^{15}$ and also didn't Hviid et al. ${ }^{16}$ between maternal use of SSRIs during pregnancy and autism spectrum disorder. ${ }^{16}$

\section{Exposure to anticonvulsants during pregnancy}

Christensen et al. ${ }^{17}$ sought associations between mothers with epilepsy who needed to take valproate during pregnancy and ASD, and demonstrated that valproate was associated with a higher risk for ASD with adjusted Hazard Ratio (AHR): 2.9 (95\% Cl, 1.7-4.9). There was also higher risk of ASD ARR: $2.2(95 \% \mathrm{Cl}, 1.02-4.9)$ among children whose mothers continued valproate during pregnancy compared to those who discontinued their medication at least 30 days prior to conception. ${ }^{17}$ 
Children exposed to valproate had poor performance on measures of verbal and memory skills compared to those exposed to other antiepileptic drugs, and non-verbal and executive functions compared to lamotrigine, but not carbamazepine or phenytoin. ${ }^{18}$

\section{Exposure to acetaminophen (paracetamol) during gestation}

Paracetamol is a widely used medication, and no medical prescription is required. ${ }^{19}$ Considered safe during pregnancy, its risk in the development of ASD has recently been proposed. ${ }^{19}$

Liew et al. ${ }^{20}$ reported that the use of acetaminophen was associated with an increased risk of ASD in children also diagnosed with hyperactivity. ${ }^{20} \mathrm{HR}: 1.51$ (95\% Cl 1.19-1.92), especially with longer duration of use beyond 20 weeks. The drug is able to cross the placental barrier and is shown to be neurotoxic due to the promotion of oxidative stress, both in vitro and in vivo. $20-23$

\section{Autism Spectrum Disorder and Vaccines}

A possible association between autism and the MMR vaccine has been raised in the global community for about 20 years and since then numerous other researches have been developed to prove or to answer such a hypothesis. A publication of April 2019 gathered the main results of this research. ${ }^{24}$

In 1999, the first ecological study in London evaluated the impact of the introduction of the triple viral vaccine under the incidence of autism, concluding that there was no association between them and no conclusions could be drawn from this phenomenon. ${ }^{24}$

All those epidemiological studies published by several countries served as source for the publication of a meta-analysis, which concluded that vaccination against measles, rubella and mumps does not increase the risk of developing ASD in children. ${ }^{24}$

\section{Exposure to alcohol during pregnancy}

Eliasen et al. ${ }^{25}$ found no positive association between ASD and mean weekly alcohol consumption, number of episodes of intoxication, and gestational age during exposure. ${ }^{25}$ Despite the absence of association, alcohol use during pregnancy is known to be highly contra indicated. ${ }^{26}$ Alcohol is a teratogenic substance that can cause various physical and behavioral effects on the fetus. The most serious condition in this spectrum of diseases is known as Fetal Alcohol Syndrome (SFA). ${ }^{26}$

\section{Exposure to smoking during pregnancy}

There was no association found between maternal smoking during pregnancy and autism in the offspring AOR: 1.16 (95\% Cl 0.97-1.40). ${ }^{27}$ Further research is therefore needed to explain this relationship more deeply.

\section{Prenatal risk factors related to clinical diseases during pregnancy}

\section{Arterial hypertension in pregnancy}

The reduction in birth weight partially moderates the association between pre-eclampsia/eclampsia and ASD..$^{10}$ Thus, the earlier it happens, the greater the chance of placental changes and consequently a higher incidence of fetal growth restriction. ${ }^{10}$

The association assessed between gestational hypertensive disorders (GHD) and the risk of ASD by the Myllennium Cohort Study (MCS) concluded that there was a significant association between GHD and a two-fold risk of ASD (95\% Cl, 1.20-3.70). It was also observed that there was neuron growth impairment, by in-vitro exposure, of rat's embryos primary cortical neurons to serum cytokines from preeclampsia pregnant women. ${ }^{28}$

\section{Diabetes Mellitus}

In order to understand the association of ASD with intra-uterine exposure to Type 2 Diabetes (T2D) and Gestational Diabetes Mellitus (GDM) ${ }^{29}$ the calculated risk was adjusted for maternal age, parity, schooling, family income, race / ethnicity, history of comorbidities and sex of the child, and yet it was showed that ASD remained associated with T2D and GDM diagnosed before 26 weeks with a HR of $1.33(95 \% \mathrm{Cl}, 1.07-1.66)$ and HR: $1.42(95 \% \mathrm{Cl}, 1.16-1.75) .{ }^{29}$ Exposure to anti diabetic medication was not found to be associated with the risk of ASD. ${ }^{29}$ 
A meta-analysis of cohort and case-control studies, that analyzed the relationship between maternal diabetes before and during pregnancy and the risk of ASD, concluded that there was a significant association between diabetes during pregnancy and the risk of ASD. ${ }^{30}$

These results suggest that the severity of maternal diabetes and time of exposure may strengthen the association between the risk of ASD in children of diabetic mothers. ${ }^{31}$

\section{Body Mass Index (BMI) and Weight Gain during pregnancy}

A study was driven in order to detect association of pre-gestational maternal BMI, as well as gestational weight gain, with the development of ASD in children. An association between obesity and ASD was found, but not significant AOR: 1.37 (95\% Cl, 0.98-1.92). ${ }^{32}$

Although it was observed that gains between 16 and $20 \mathrm{~kg}$ showed an AOR: $1.52(95 \% \mathrm{Cl}, 1.05-2.22)$ and gains greater than $20 \mathrm{~kg}$ an AOR: $1.58(95 \% \mathrm{Cl}, 1.08-2.31) .32$ At each $2.3 \mathrm{~kg}$ gain the chances of developing autism increased by $6 \%$; with AOR: $1.06(95 \% \mathrm{Cl}, 1.02-1.10){ }^{32}$

\section{Risk factors during child birth}

Analyzing type of birth and risk of developing ASD, its reported that the following outcomes might raise it: cesarean delivery RR: 1.30 (95\% Cl, 1.15-1.48), prematurity RR: 1.31 (95\% Cl, 1.16-1.48), induction of labor RR: 1.11 (95\% Cl, 1.04-1.20), absence of labor RR: $1.23(95 \% \mathrm{Cl}, 1.09-1.39)$, as well as breech presentation RR: 1.47 (95\% Cl, 1.23-1.76). It was also found that a nuchal cord, prerogative for fetal hypoxemia, had a RR: 1.87 ( $95 \% \mathrm{Cl}$, 0.56- 6.19), premature rupture of membranes RR: $2.30(95 \% \mathrm{Cl}, 0.38-14.11)$, but were not considered as significant risk factors in this sample. ${ }^{7}$ Parity greater than or equal to 4 was considered as a protection factor RR: $0.73(95 \% \mathrm{Cl}, 0.66-0.81){ }^{7}$

\section{Drug use during labor}

Fetuses exposed to drugs use during labor, including oxytocin and anesthetics, had an increased risk of 2.7 fold of ASD. However, the duration of exposure to medications measured during labor, as a risk factor for the development of ASD, was not significant. ${ }^{33}$

\section{Other risk factors}

The following factors: low birth weight RR: 1.26 (95\% Cl, $1.20-1.34)$, postpartum bleeding RR: 2.10 (95\% Cl, 1.30-3.40), male sex RR: 1.47 (95\% Cl, 1.39-1.55) showed a statistically significant association for ASD. In the other hand the fifth minute Apgar score lower than 7 RR: 1.43 (95\% Cl, 0.95- 2.14), respiratory tract infection RR: $2.64(95 \% \mathrm{Cl}, 0.78-8.6)$ showed no association with autism in a meta-analysis. ${ }^{7}$ Being a female was a protective factor RR: 0.37 (95\% Cl, $\left.0.34-0.41\right){ }^{7}$

There is evidence that the need for extra neonatal care as: hospitalization in an intensive care unit OR: $1.25(95 \% \mathrm{Cl}, 0.9-1.8)$ or semi-intensive OR: 1.40 with $95 \% \mathrm{Cl}$ (1.02 to 1.9) had a slightly higher chance of childhood autism. ${ }^{1}$

To test the hypothesis of cumulative environmental and early medical events and ASD as well as autistic traits, a study was carried out in monozygotic twins discordant for ASD and monozygotic with normal development. They observed that monozygotic twins with autism differed from their non-autistic siblings as to the burden of early cumulative medical events and that they had higher levels of disregulations in the first year of life caused by non-shared environmental factors. ${ }^{34}$

\section{CONCLUSIONS}

Knowing that the etiology of ASD is comprised in a genetic-environment binomial, it was observed that variables such as socio-economic factors, age, educational level were shown to be relevant.

The prenatal care strategy maintains a high level of importance, due to the possibility of preventing aggravating factors that may contribute to maternal-fetal exposure (T2D, DMG, GHD, abuse of medications) and the development of autistic disorder in children. It is incumbent upon health professionals to pay attention, even during the postnatal period and during child care, to those children who have been exposed to these described risk factors, so that early warning signs an early diagnosis of ASD can be done and pursuit correct management.

\section{Acknowledgments:}

To the family and friends who supported us to carry out this study. To Ms. Isabela T. Rosado Schmaltz for reviewing the translation. 


\section{REFERENCES}

1. Polo-Kantola P, Lampi KM, Hinkka-Yli-Salomäki S, Gissler M, Brown AS, Sourander A. Obstetric risk factors and autism spectrum disorders in Finland. J Pediatr. 2014;164(2):358-65. http://dx.doi.org/10.1016/j.jpeds.2013.09.044. PMid:24183209.

2. Hallmayer J, Cleveland S, Torres A, Phillips J, Cohen BAB, Torigoe BAT, et al. Genetic heritability and shared environmental factors among twin pairs with autism. Arch Gen Psychiatry. 2011;68(11):1095-102. http://dx.doi.org/10.1001/archgenpsychiatry.2011.76. PMid:21727249.

3. Froehlich-Santino W, Tobon AL, Cleveland S, Torres A, Phillips J, Cohen B, et al. Prenatal and perinatal risk factors in a twin study of autism spectrum disorders. J Psychiatr Res. 2014;54:100-8. http://dx.doi.org/10.1016/j.jpsychires.2014.03.019. PMid:24726638.

4. Pignatari G. CDC divulga novos números de autismo nos EUA: 1 para 59 [Internet]. São Paulo: Tiismo; 2018 [cited 2018 Aug 6]. Available from: https://tismoo.us/destaques/cdc-divulga-novos-numeros-de-autismo-nos-eua-1-para-59/

5. Fombonne E. Epidemiology of pervasive developmental disorders. Pediatr Res. 2009;65(6):591-8. http://dx.doi.org/10.1203/ PDR.0b013e31819e7203. PMid:19218885.

6. Klin A. Autism and Asperger syndrome: an overview. Rev Bras Psiquiatr. 2006;28(Supl I):S3-11. http://dx.doi.org/10.1590/S151644462006000500002. PMid:16791390.

7. Wang C, Geng H, Liu W, Zhang G. Prenatal, perinatal, and postnatal factors associated with autism: a meta-analysis. Medicine. 2017;96(18):e6696. http://dx.doi.org/10.1097/MD.0000000000006696. PMid:28471964.

8. Abdullahi I, Wong K, Mutch R, Glasson EJ, De Klerk N, Cherian S, et al. Risk of developmental disorders on children of immigrant mothers: a population-based data linkage evaluation. J Pediatr. 2019;204(3):275-84.e3. http://dx.doi.org/10.1016/j.jpeds.2018.08.047. PMid:30293641.

9. Brimacombe M, Ming X, Lamendola M. Prenatal and birth complications in autism. Matern Child Health J. 2007;11(1):73-9. http:// dx.doi.org/10.1007/s10995-006-0142-7. PMid:17053965.

10. Mann JR, McDermott S, Bao H, Hardin J, Gregg A. Pre-eclampsia, birth weight, and autism spectrum disorders. J Autism Dev Disord. 2010;40(5):548-54. http://dx.doi.org/10.1007/s10803-009-0903-4. PMid:19936906.

11. Surén $P$, Roth $C$, Bresnahan M, Haugen M, Hornig M, Hirtz D, et al. Association between maternal use of folic acid supplements and risk of autism spectrum disorders in children. JAMA. 2013;309(6):570-7. http://dx.doi.org/10.1001/jama.2012.155925. PMid:23403681.

12. Steenweg-de Graaff J, Ghassabian A, Jaddoe VW, Tiemeier H, Roza SJ. Folate concentrations during pregnancy and autistic traits in the offspring: the generation R study. Eur J Public Health. 2015;25(3):431-3. http://dx.doi.org/10.1093/eurpub/cku126. PMid:25085472.

13. Rai D, Lee BK, Dalman C, Newschaffer C, Lewis G, Magnusson C. Antidepressants during pregnancy and autism in offspring: population based cohort study. BMJ. 2017;358:j2811. PMid:28724519.

14. Croen LA, Grether JK, Yoshida CK, Odouli R, Hendrick V. Antidepressant use during pregnancy and chilhood autism spectrum disorders. Arch Gen Psychiatry. 2011;68(11):1104-12. http://dx.doi.org/10.1001/archgenpsychiatry.2011.73. PMid:21727247.

15. Sørensen MJ, Gronborg TK, Christensen J, Parner ET, Vestergaard M, Schendel D, et al. Antidepressant exposure in pregnancy and risk of autism spectrum disorders. Clin Epidemiol. 2013;5:449-59. http://dx.doi.org/10.2147/CLEP.S53009. PMid:24255601.

16. Hviid A, Melbye M, Pasternak B. Use of selective serotonin reuptake inhibitors during pregnancy and risk of autism. $\mathrm{N}$ Engl J Med. 2013;369(25):2406-15. http://dx.doi.org/10.1056/NEJMoa1301449. PMid:24350950.

17. Christensen J, Gronborg TK, Sorensen MJ, Schendel D, Parner ET, Pedersen LH, et al. Prenatal valproate exposure and risk of autism spectrum disorders and childhood autism. JAMA. 2013;309(16):1696-703. http://dx.doi.org/10.1001/jama.2013.2270. PMid:23613074.

18. Meador KJ, Baker GA, Browning N, Cohen MJ, Bromley RL, Clayton-Smith J, et al. Fetal antiepileptic drug exposure and cognitive out comes at age 6 years (NEAD study): a prospective observation al study. Lancet Neurol. 2013;12(3):244-52. http://dx.doi. org/10.1016/S1474-4422(12)70323-X. PMid:23352199.

19. Andrade C. Use of acetaminophen (paracetamol) during pregnancy and the risk of autism spectrum disorder in the offspring. J Clin Psychiatry. 2016;77(2):e152-4. http://dx.doi.org/10.4088/JCP.16f10637. PMid:26930528.

20. Liew Z, Ritz B, Virk J, Olsen J. Maternal use of acetaminophen during pregnancy and risk of autism spectrum disorders in childhood: a danish national birth cohort study. Autism Res. 2016;9(9):951-8. http://dx.doi.org/10.1002/aur.1591. PMid:26688372.

21. Albert O, Desdoits-Lethimonier C, Lesné L, Legrand A, Guillé F, Bensalah F, et al. Paracetamol, aspirin and indomethacin display endocrine disrupting properties in the adult humantestis in vitro. Hum Reprod. 2013;28(7):1890-8. http://dx.doi.org/10.1093/ humrep/det112. PMid:23670170.

22. Frye CA, Bo E, Calamandrei G, Calzá L, Dessi-Fulgheri F, Fernandéz M, et al. Endocrine disrupters: a review of some sources, effects, and mechanisms of actions on behavior and neuroendocrine systems. J Neuroendocrinol. 2012;24(1):144-59. http:// dx.doi.org/10.1111/j.1365-2826.2011.02229.x. PMid:21951193.

23. Ghanizadeh A. Acetaminophen may mediate oxidative stress and neurotoxicity in autism. Med Hypotheses. 2012;78(2):351. http://dx.doi.org/10.1016/j.mehy.2011.11.009. PMid:22154541.

24. DeStefano F, Shimabukuro TT. The MMR vaccine and autism. Annu Rev Virol. 2019;6(1):585-600. http://dx.doi.org/10.1146/ annurev-virology-092818-015515. PMid:30986133. 
25. Eliasen M, Tolstrup JS, Nybo Andersen AM, Grønbaek M, Olsen J, Strandberg-Larsen K. Prenatal alcohol exposure and autistic spectrum disorders- a population-based prospective study of 80552 children and their mothers. Int J Epidemiol. 2010;39(4):107481. http://dx.doi.org/10.1093/ije/dyq056. PMid:20371506.

26. Gupta KK, Gupta VK, Shirasaka T. An update on fetal alcohol syndrome-pathogenesis, risks, and treatment. Alcohol Clin Exp Res. 2016;40(8):1594-602. http://dx.doi.org/10.1111/acer.13135. PMid:27375266.

27. Jung Y, Lee AM, McKee SA, Picciotto MR. Maternal smoking and autism spectrum disorder: meta-analysis with population smoking metrics as moderators. Sci Rep. 2017;7(1):4315. http://dx.doi.org/10.1038/s41598-017-04413-1. PMid:28659613.

28. Curran EA, O'Keeffe GW, Looney AM, Moloney G, Hegarty SV, Murray DM, et al. Exposure to hypertensive disorders of pregnancy increases the risk of autism spectrum disorder in affected offspring. Mol Neurobiol. 2018;55(7):5557-64. http://dx.doi.org/10.1007/ s12035-017-0794-x. PMid:28975539.

29. Xiang AH, Wang X, Martinez MP, Walthall JC, Curry ES, Page K, et al. Association of maternal diabetes with autism in offspring. JAMA. 2015;313(14):1425-34. http://dx.doi.org/10.1001/jama.2015.2707. PMid:25871668.

30. Xu G, Jing J, Bowers K, Liu B, Bao W. Maternal diabetes and the risk of autism spectrum disorders in the offspring: a systematic review and meta-analysis. J Autism Dev Disord. 2014;44(4):766-75. http://dx.doi.org/10.1007/s10803-013-1928-2. PMid:24057131.

31. Xiang AH, Wang $X$, Martinez MP, Page K, Buchanan TA, Feldman RK. Maternal type 1 diabetes and risk of autism in offspring. JAMA. 2018;320(1):89-91. http://dx.doi.org/10.1001/jama.2018.7614. PMid:29936530.

32. Windham GC, Anderson M, Lyall K, Daniels JL, Kral TVE, Croen LA, et al. Maternal pre-pregnancy body mass index and gestacional weight gain in relation to autism spectrum disorder and other developmental disorders in offspring. Autism Res. 2019;12(2):31627. http://dx.doi.org/10.1002/aur.2057. PMid:30575327.

33. Smallwood M, Sareen A, Baker E, Hannusch R, Kwessi E, Williams T. Increased risk of autism development in children whose mothers experienced birth complications or received labor and delivery drugs. ASN Neuro. 2016;8(4):1-7. http://dx.doi. org/10.1177/1759091416659742. PMid:27511908.

34. Willfors C, Carlsson T, Anderlid B-M, Nordgren A, Kostrzewa E, Berggren S, et al. Medical history of discordant twins and environment al etiologies of autism. Transl Psychiatry. 2017;7(1):e1014. http://dx.doi.org/10.1038/tp.2016.269. PMid:28140403.

Corresponding author:

Luiza Emylce Pelá Rosado. Address: Avenida T15 nº 800 Apartamento 1702, Setor Bueno - Goiânia - Goiás CEP: 74230-010. Email: draluiza. rosado@gmail.com

\section{Author information}

Luiza Emylce Pelá Rosado is Gynecologist and Obstetrician, Master and finishing Doctor degree in Epidemiology by Federal University of Goiás. Coordinator of the Medical Residency in Obstetrics at Hospital Materno Infantil of Goiânia and Professor in Human Reproduction at Pontificial University of Goiás; Goiânia, Goiás, Brasil email: draluiza.rosado@gmail.com; Matheus Maia Garcia and Ana Cláudia do Nascimento Coutinho are Medical Doctors by Pontificial University of Goiás; Goiânia, Goiás, Brasil.

\section{Contribution of each co-author:}

Luiza E P Rosado participated in conceiving and designing the study, academic guidance and critical review of the intellectual contente, including English review. Matheus M Garcia and Ana Cláudia N Coutinho participated in the selection and analysis of the information collected, writing the article and transcribing it into English. 